\title{
Comparison of daily and intermittent anti tubercular treatment in achieving sputum negativity in newly diagnosed sputum positive Pulmonary tuberculosis patients
}

\author{
Thorve Swapnil M ${ }^{1}$, Dhamgaye T. M. ${ }^{2}$ \\ ${ }^{1}$ Dr Thorve Swapnil M., Consultant, Pulmonary Medicine, HBT Medical College and RN Cooper Hospital, Mumbai, ${ }^{2}$ Dr \\ Dhamgaye T. M., HOD Pulmonary Medicine, B. J. Medical College, Pune, Maharashtra, India
}

Address for correspondence: ${ }^{1}$ Dr Thorve Swapnil M, Email: thorves@yahoo.com

\begin{abstract}
Introduction: Tuberculosis is a major health problem in India. Sputum positive pulmonary tuberculosis patients expel bacilli for a variable period after the start of treatment. The period of infectivity depends on the drugs, dosage and interval period. Achieving sputum negativity helps in reducing secondary cases. Aim: Comparison of the effectiveness of daily and intermittent anti tubercular treatment in achieving sputum negativity in newly diagnosed sputum positive pulmonary tuberculosis patients without comorbidities. Methods: A prospective study was carried out in BJMC and SGH, Pune. 71 sputum positive pulmonary tuberculosis patients were included in the study. 35 patients received daily treatment and 36 patients received intermittent treatment. Patients were followed up on $15^{\text {th }}, 30^{\text {th }}, 45^{\text {th }}$ and $60^{\text {th }}$ day of treatment. Results: Mean duration of sputum conversion was 29 days in daily treatment and 44 days in intermittent treatment. Patients on daily regimen have sputum conversion about 15 days earlier as compared to intermittent regimen. ( $\mathrm{p}<0.05$ ). Conclusion: Patients on daily treatment are sputum negative 15 days prior to patients on intermittent treatment. Using daily treatment will decrease the period of communicability. Thus daily treatment will decrease the incidence and prevalence of the disease in a country with heavy burden of tuberculosis. A cost effective approach will be daily treatment during intensive phase and intermittent treatment during continuation phase.
\end{abstract}

Key words: Pulmonary tuberculosis, Daily treatment, Intermittent treatment, Sputum positive

\section{Introduction}

Tuberculosis is a major public health problem in India and worldwide. According to the World Health Organization (WHO) global TB report of 2015[1], India accounts for $26 \%$ of the total global TB burden. 2.0-2.5 million new cases are added annually. Out of all TB notified cases in India, 53\% are smear positive cases, $28 \%$ are smear negative cases and $19 \%$ are extra pulmonary cases. It is estimated that $2.2 \%$ cases of TB in India are of MDR TB. $4 \%$ of patients of TB in India are HIV positive [2]. TB cases are increasing worldwide after HIV epidemic and development of multidrug resistance tuberculosis. Tuberculosis is a treatable disease and can be treated with various regimens. Both daily and intermittent regimen can be used for treatment of tuberculosis. The intermittent regimen can be as

\footnotetext{
Manuscript received $15^{\text {th }}$ September 2016

Reviewed: $24^{\text {th }}$ September 2016

Author Corrected: $02^{\text {nd }}$ October 2016

Accepted for Publication $10^{\text {th }}$ October 2016
}

effective as the daily regimen [3]. It has the advantage of a directly observed therapy which ensures a compliance [4]. Following an external review of the National TB Programme in 1992, the Revised National TB Control Programme (RNTCP) was formulated. The RNTCP addressed the weaknesses of the NTP noted by the 1992 review, and adapted to the Indian setting the globally recommended "DOTS Strategy" for TB control. After a pilot phase (1993 - 97), RNTCP was scaled up in a phased manner to cover the entire country by March 2006. The main principle of DOTS is that a directly observed therapy which ensures compliance and a regular treatment with high quality drugs prevents drug resistance. DOTS is the internationally recommended strategy for ensuring the cure of TB. The case detection is done by sputum smear microscopy [2]. The main focus is to stop the chain of the transmission, to decrease the new $\mathrm{TB}$ cases and decrease the 
development of multidrug resistant tuberculosis [5]. For patients receiving Category 1 regimen in RNTCP, smear conversion at the end of intensive phase (IP) of treatment is considered as a predictor of treatment $[6,7]$.

Even after introduction of DOTS in India tuberculosis remains the leading cause of morbidity and mortality in India. TB kills 2 persons every 3 minutes (1000/day). The numbers of sputum smear positive cases are 41 per lakh of population [1]. Association with co-morbid conditions like diabetes mellitus and HIV leads to further increase in incidence. MDR TB is posing a new threat.

In fifth pacific, Stop TB meeting of WHO, May 2010, WHO recommended, "wherever feasible, the optimal dosing frequency for new patients with pulmonary TB is daily throughout the course of therapy "[8].

There are few studies which compare daily and intermittent regimens and sputum conversion at the end of intensive phase of DOTS. This study compares daily treatment with intermittent treatment which is used in RNTCP DOTS, and finds the time of sputum conversion.

\section{Aims and Objectives}

1. To compare outcome of daily and intermittent regimen on sputum conversion during intensive phase in newly diagnosed sputum positive pulmonary tuberculosis cases without HIV.

2. To compare the effectiveness of the daily and intermittent regimen in reducing the bacillary load and the infectivity of sputum positive cases.

\section{Materials and Methods}

All patients attending OPD having cough for a period of more than 2 weeks were investigated for acid fast bacilli by sputum $\mathrm{ZN}$ staining. Patients who were sputum smear positive were included in the study. Detailed clinical history was taken and examination was carried. Patients were investigated with chest roentgenogram, HIV ELISA, random blood sugar and other investigations if required.

\section{Inculsion Criteria}

\section{Results}

The study comprised of 71 patients. Out of 71 patients, 35 patients were initiated on daily antituberculosis treatment and 36 patients were initiated on intermittent antituberculosis treatment.
A. Sputum smear positive.
B. New case.
C. Weight $>35 \mathrm{~kg}$.
D. Age 10-65 years.
E. Willing to participate and give informed consent after going through the terms and conditions of the trial.

\section{Exculsion Criteria}

B. History of contact with drug resistant TB patient.

C. HIV positive patient.

D. Patients critically ill and difficult to follow up.

E. Moribund, bedridden or unconscious patients.

F. Co-morbid conditions like uncontrolled diabetes mellitus, cardiac failure, malignancy at initial presentation and major psychiatric illness.

Patients found to be newly diagnosed sputum positive without HIV were selected and divided in to two groups. The first group was given daily treatment and the other was given intermittent thrice weekly treatment as per RNTCP DOTS.For daily regimen, Patients received Isoniazid $(5 \mathrm{mg} / \mathrm{kg})$, rifampicin $(10 \mathrm{mg} / \mathrm{kg})$, pyrazinamide $(25-30 \mathrm{mg} / \mathrm{kg})$ and ethambutol (15$20 \mathrm{mg} / \mathrm{kg}$ ) during intensive phase and isoniazid $(5 \mathrm{mg} / \mathrm{kg})$ and rifampicin $(10 \mathrm{mg} / \mathrm{kg})$ during continuation phase.

For intermittent regimen the doses were given as per RNTCP DOTS and treatment was thrice weekly.

Patients received Isoniazid 600mg, rifampicin $450 \mathrm{mg}$, pyrazinamide $1500 \mathrm{mg}$ and ethambutol $1200 \mathrm{mg}$ during intensive phase $600 \mathrm{mg}$ and isoniazid and rifampicin 450 during continuation phase.

Patients were followed up regularly at an interval of 15 days. Sputum microscopy for AFB was done during follow up. Sputum conversion rate was compared on $15^{\text {th }}, 30^{\text {th }}, 45^{\text {th }}$ and $60^{\text {th }}$ day of treatment.

Patients were also observed for adverse effects of drugs during the course of treatment during the follow up. Gastrointestinal symptoms, rashes and itching, flushing, headache, tingling and burning sensations, peripheral neuropathy, arthralgia, blurring of vision and fever were enquired.
A. Deranged liver or kidney function. 
The male:female ratio was 2.55:1.

Table-1: Sex distribution in the study

\begin{tabular}{|c|c|c|c|}
\hline Regimens & Males & Females & Ratio ( M:F ) \\
\hline Daily regimen & 24 & 11 & $2.18: 1$ \\
\hline Intermittent regimen & 27 & 09 & $3: 1$ \\
\hline Total & 51 & 20 & $2.55: 1$ \\
\hline
\end{tabular}

Most of the patients in the study were in the third and fourth decade of life. $73.23 \%$ of the patients were less than 30 years old.

Table-2: Age distribution in study

\begin{tabular}{|c|c|c|c|}
\hline Age ( in years ) & $\begin{array}{c}\text { No. of patients on Daily } \\
\text { regimen }\end{array}$ & $\begin{array}{c}\text { No. of patients on } \\
\text { Intermittent regimen }\end{array}$ & Total no. of patients \\
\hline $11-20$ & 04 & 06 & 10 \\
\hline $21-30$ & 08 & 09 & 25 \\
\hline $31-30$ & 12 & 13 & 11 \\
\hline $41-50$ & 07 & 04 & 05 \\
\hline $51-60$ & 03 & 02 & 03 \\
\hline $61-65$ & 01 & 02 & $\mathbf{7 1}$ \\
\hline Total & $\mathbf{3 5}$ & $\mathbf{3 6}$ & \\
\hline
\end{tabular}

Daily treatment: 35 patients were given daily treatment. 3 patients $(8.57 \%)$ defaulted and 1 patient had severe jaundice and thus was started on Non DOTS regimen. Out of 31 patients who followed up regularly, 30 patients (96.77\%) were sputum smear negative at the end of the intensive phase of treatment. 1 patient (3.2\%) was positive at the end of intensive phase who was given extension of intensive phase for 1 month.

Follow up sputum was negative after 1 month.

Out of these 31 patients, sputum conversion was seen in 9 patients on $15^{\text {th }}$ day, 25 patients on $30^{\text {th }}$ day, 28 patients on $45^{\text {th }}$ day and 30 patients on $60^{\text {th }}$ day. The mean duration of sputum conversion was 29 days with standard deviation of 12.41 .

Intermittent treatment: 36 patients were given intermittent treatment. 2 patients $(5.5 \%)$ defaulted. Out of 34 patients who followed up regularly 32 patients $(94.11 \%)$ were sputum smear negative at the end of the intensive phase. 2 patients $(6.25 \%)$ remained sputum positive after intensive phase.

Both patients were given 1 month of extension of intensive phase. Amongst them 1 patient was sputum negative after 1 month. The other was subsequently started on category 2 DOTS.

Out of these 34 patients, sputum conversion was seen in 1 patients on $15^{\text {th }}$ day, 8 patients on $30^{\text {th }}$ day, 26 patients on $45^{\text {th }}$ day and 32 patients on $60^{\text {th }}$ day of treatment.

The mean duration of treatment at which sputum conversion occurred was 44 days (approximately) with a standard deviation of 11.01 .

Table-3: Default rate in daily and intermittent regimens

\begin{tabular}{|c|c|c|}
\hline Regimens & No. of patients defaulted & Default rate \\
\hline Daily regimen & 3 & $8.57 \%$ \\
\hline Intermittent regimen & 2 & $5.5 \%$ \\
\hline Total & 5 & $7.04 \%$ \\
\hline
\end{tabular}




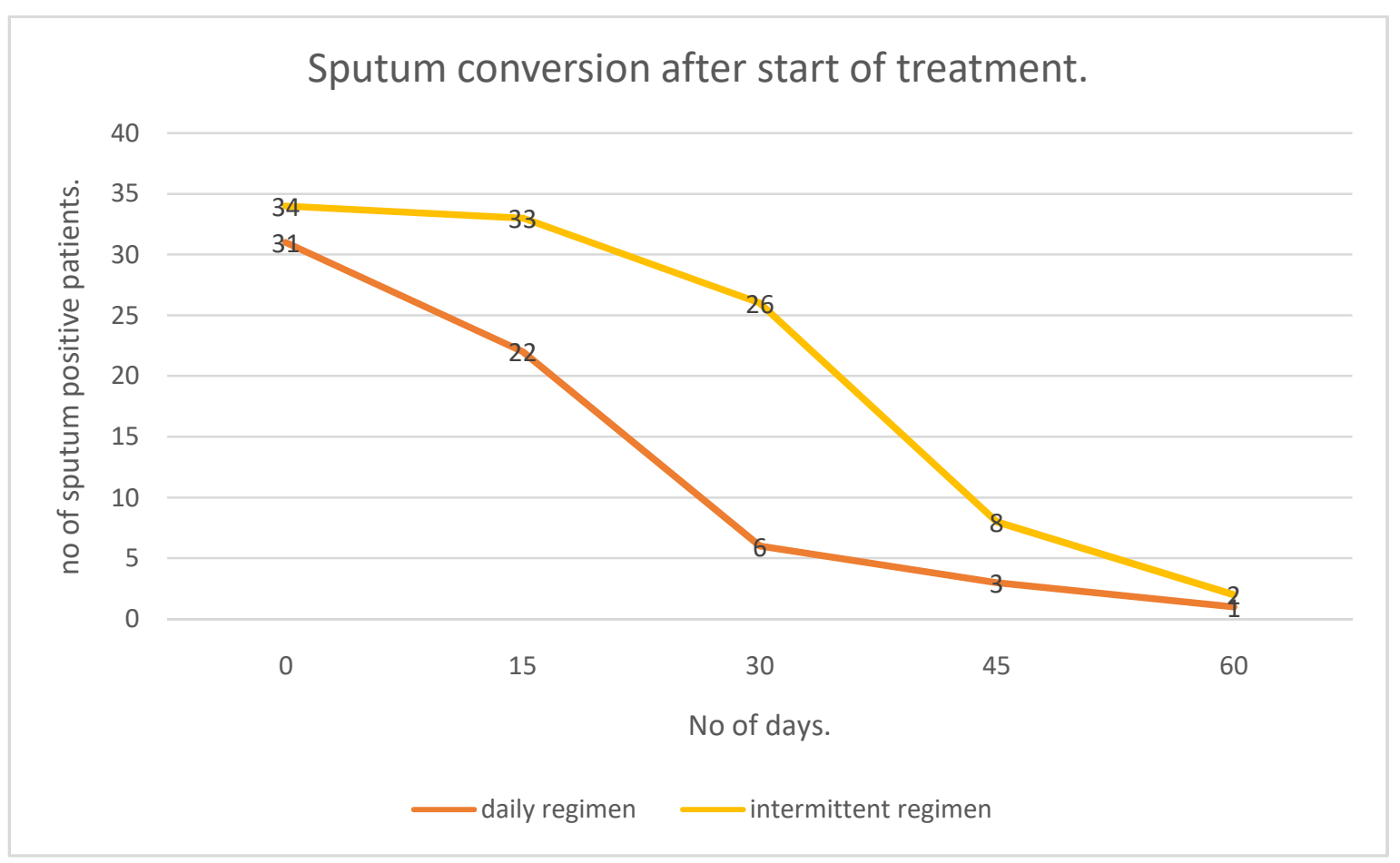

Figure-1: Trend in sputum conversion after starting treatment

Table-4: Sputum conversion in daily and intermittent regimen

\begin{tabular}{|c|c|c|}
\hline \multirow{2}{*}{$\begin{array}{c}\text { Days after start of treatment } \\
\text { (in days ) }\end{array}$} & \multicolumn{2}{|c|}{ Sputum conversion } \\
\cline { 2 - 3 } & Daily regimen & Intermittent regimen \\
\hline 0 & 0 & 0 \\
\hline 15 & 9 & 1 \\
\hline 30 & 25 & 8 \\
\hline 45 & 28 & 26 \\
\hline 60 & 30 & 32 \\
\hline
\end{tabular}

Patients on daily treatment had sputum conversion 15 days earlier when compared with intermittent regimen. (p $<0.05)$

\section{Discussion}

Tuberculosis epidemiology is known to vary in endemic and non-endemic countries. Majority of data available on sputum conversion has been from developed countries. Various regimens are used to treat tuberculosis in modern practice. RNTCP India recommends DOTS strategy which is based on intermittent regimens for treatment of tuberculosis. The DOTS programme, implemented in India, has produced remarkable clinical and epidemiological results.

The treatment success rate of smear-positive cases doubled (40\% before and $80 \%$ after DOTS); and the death rate became one-seventh $(29 \%$ before and $4 \%$ after DOTS)[9]. A longitudinal study in Tiruvallur area (South India)[12] reported that during a 30-year period prior to DOTS, the annual decline in the prevalence of culture-positive and smear-positive cases were $2.3 \%$ and $2.5 \%$ respectively.

In India $40 \%$ of population is infected with TB and $60 \%$ patients infected with TB are in economically productive age group. In our study, $59.15 \%$ of patients were in the age group of 20-40 years.

Philips noted in 1960's that about half of the new cases of PTB occurred in those who were at least 45 years old, and the relative incidence was highest in those who were more than 65 years of age.[13] In our study, $71.83 \%$ patients are males and $28.16 \%$ patients are females. The male: female ratio is $2.55: 1$. Other studies 
have shown that, the prevalence as well as incidence of tuberculosis is higher among males than among females, the ratio varying from $3: 1$ to $5: 1$.

In a study of 2434 cases of pulmonary tuberculosis by Deshmukh [14] and others, it was reported that $62.9 \%$ were males and $37.1 \%$ were females.Tripathy and Kar reported that $78 \%$ of their patients were males [15]. Patel JC showed a similar ratio of male: female. In the 179 cases he studied, $76 \%$ were males and $24 \%$ were females. Morris and others also in their study observed that male population outnumbered the females [16].

We undertook this study to gain insight into time to sputum conversion as proxy measure of noninfectiousness. It is found that both daily and intermittent regimens are equally successful in sputum conversion by the end of intensive phase. But it is found that the sputum conversion occurred on $29^{\text {th }}$ day of daily treatment and $44^{\text {th }}$ day (approximately) on intermittent treatment. The difference of sputum conversion between the two regimens is statistically significant ( $p$ $<0.05$ ). Thus a case of sputum positive pulmonary tuberculosis on daily treatment will be less infectious by 15 days. The number of secondary cases arising from a sputum positive patient will decrease as the time period of infectiousness will reduce. This will eventually lead to decrease in incidence and prevalence of tuberculosis. Countries like India with heavy burden of diseases will be benefited with daily regimen. A cost effective approach will be daily treatment during intensive phase and intermittent treatment during continuation phase.

Similar studies $[7,8,9,10,11]$ showed that daily treatment was superior in achieving sputum negativity at early stage of treatment.

The fifth pacific stop TB meeting was held in May 2010 at Nadi, Fiji [8] to inform the participants about the guidelines for treatment of tuberculosis. It was recommended that for newly diagnosed TB patients, daily treatment should be used wherever feasible (with high grade of evidence). Daily treatment during intensive phase and intermittent treatment during continuation phase is recommended with moderate grade of evidence. According to guidelines, patients receiving intermittent treatment throughout therapy have higher rates of drug resistance when compared with patients receiving daily treatment throughout therapy or during intensive phase. For HIV positive TB patients and all TB patients living in HIV prevalent area, it is recommended to use daily treatment throughout therapy with high grade of evidence.

\section{Conclusion}

1. At the end of intensive phase of treatment (end of 2 months), sputum conversion in daily and intermittent regimen was almost similar.

2. This study compares the sputum conversion at $15^{\text {th }}$, $30^{\text {th }}, 45^{\text {th }}$ and $60^{\text {th }}$ day. It was found that mean duration of sputum conversion was 29 days in daily treatment and 44days in intermittent treatment. Patients on daily regimen have sputum conversion about 15 days earlier as compared to intermittent regimen. $(\mathrm{p}<0.05)$. Thus using daily regimen will lead to decrease in period of infectiousness. This will reduce the number of secondary cases and will further lead to decrease in incidence and prevalence of disease in a country like India with a heavy burden of tuberculosis.

\section{Recommendations:}

1. Sputum positive pulmonary tuberculosis patients should be treated with daily regimen as sputum negativity is achieved earlier in disease course and thus will decrease the spread of infection.

2. If daily regimen is financially not feasible daily treatment should be given in the intensive phase (initial 2 months)

Funding: Nil, Conflict of interest: None initiated, Permission from IRB: Yes

\section{References}

$1 . \quad$ "Global

TB

Report".

www.who.int/tb/publications/global_report, 2015.

2. "RNTCP India Training Module 1-4". www.tbcindia.nic.in, 2010.

3. Global tuberculosis control surveillance planning financing report, www.who.int/tb, 2012.

4. Srinath S, Sharath B, Santosha K, Chadha SS, Roopa S, Chander K, Wares F, Chauhan LS, Wilson NC, Harries AD. Tuberculosis 'retreatment others': profile and treatment outcomes in the state of Andhra Pradesh, India. Int J Tuberc Lung Dis. 2011 Jan;15(1):105-9.

5. Tuberculosis Chemotherapy Centre (Indian Council of Medical Research),Chennai. Low rate of emergence of drug resistance in sputum positive patients treated 
with short-course chemotherapy. Int $\mathbf{J}$ Tubercle Lung Dis 2001;5(1):40-45.

6. Naude TM, Jim M. Twice weekly vs. daily chemotherapy for childhood tuberculosis. Pediatric Infectious Disease Journal:2000;19:405-410.

7. Parikh R, Nataraj G, Kanade S, Khatri V, Mehta P. Time to sputum conversion in smear positive pulmonary TB patients on category I DOTS and factors delaying it. J Assoc Physicians India. 2012 Aug;60:226.

8. Treatment of tuberculosis guidelines. Technical paper, 5th pacific, Stop TB meeting, Nadi, Fiji, May 2010

9. Banu Rekha VV, Balsubramanian R, Swaminathan $\mathrm{S}$. Sputum conversion at the end of intensive phase treatment of pulmonary tuberculosis patients with diabetes mellitus or HIV infection. Indian J Med Res. 2008 April:408-409

10. Menon PR, Lodha R, Sivanandan S, Kabra SK. Intermittent or daily short course chemotherapy for tuberculosis in children: meta-analysis of randomized controlled trials. Indian Pediatr. 2010 Jan;47(1):67-73. Epub 2009 May 20.
11. Hong Kong Chest Service / British Medical Research Council. Controlled trial of 4 three-timesweekly regimens and a daily regimen all given for 6 months for pulmonary tuberculosis, Second report: The results up to 24months. Tubercle 1982;63:89-98.

12. Subramani R, Santha T, Frieden TR, Radhakrishna S, Gopi PG, Selvakumar N, Sadacharam K, et al. Active Community surveillance of the impact of different tuberculosis Control measure, Tiruvallur, South India,1968-2001. Int. J. Epidemiol Advance Access, 2006:1-7.

13. Philips S. A view of the overall problem, In: S. Philips(Ed) Current problems in tuberculosis. Springfield, Charles C Thomas Publ. 1966:109-15.

14. Deshmukh PA, Shaw T. Pulmonary tuberculosis and diabetes mellitus. Ind J Tub 1984;31:114.

15. Tripathy SR, Kar KP, Chakraborthy DC, Majumdar AK. Diabetes mellitus and pulmonary tuberculosis - A prospective study. Ind J Tub 1984;31:122.

16. Patel JC. Complications in 8793 cases of diabetes mellitus, 14 years study in Bombay Hospital, Bombay, India. Ind J Med Sci 1989;43:177.

\section{How to cite this article?}

Thorve Swapnil M , Dhamgaye T. M.. Comparison of daily and intermittent anti tubercular treatment in achieving sputum negativity in newly diagnosed sputum positive Pulmonary tuberculosis patients. Int J Med Res Rev 2016;4(10):1744-1749.doi:10.17511/ijmrr. 2016.i10.05. 